\title{
Comparison between adult and infant lung injury in a rabbit ischemia-reperfusion model
}

\author{
Wanshan Qiu, MD, a,b,c Liang Zheng, MD, ${ }^{a}$ Haiyong Gu, MD, ${ }^{a}$ Duan Chen, MD, $\mathrm{PhD},{ }^{c}$ and Yijiang Chen, $\mathrm{MD}^{\mathrm{a}}$
}

Objective: Ischemia-reperfusion causes lung damage to patients with congenital heart disease who undergo open surgery under total cardiopulmonary bypass. The aim of the present study was to compare ischemia-reperfusion-induced lung damage between adults and infants.

Methods: Both infant (15 to 21-day-old) and adult (5 to 6-month-old) rabbits were subjected to either ischemia-reperfusion or sham operation. Ischemia-reperfusion was induced by clamping the right pulmonary hilum for 1 hour and then removing the clamp for 4 hours. The lung tissue samples were collected for histologic examination by light and electron microcopies and for biological evaluation of mitochondrial alterations. Blood samples were taken for measurement of interleukin- $1 \beta$ and tumor necrosis factor- $\alpha$. Differences among the groups were analyzed by 2 -way analysis of variance.

Results: In comparison with adult lungs, the infant lungs had increased neutrophil infiltration, edema, swollen alveolar epithelial and endothelial cells, and severe mitochondrial impairment reflected by reduced swelling rate and membrane potential, intramitochondrial free $\mathrm{Ca}^{2+}$ levels after ischemia-reperfusion. The infant lungs produced higher levels of hydroxyl radical and malondialdehyde and lower levels of superoxide dismutase and glutathione peroxidase than adult lungs, especially after ischemia-reperfusion. The circulating levels of interleukin- $1 \beta$ and tumor necrosis factor- $\alpha$ were elevated during ischemia-reperfusion, particularly in the infants, which appeared to be associated with the expression of myeloid differentiation factor- 88 and

From the Department of Thoracic and Cardiovascular Surgery, The First Affiliated Hospital of Nanjing Medical University, ${ }^{a}$ Nanjing, China; Department of Thoracic and Cardiovascular Surgery, The Affiliated Children's Hospital of Nanjing Medical

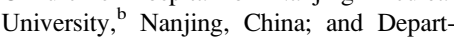
ment of Cancer Research and Molecular Medicine, Norwegian University of Science and Technology, ${ }^{\mathrm{c}}$ Trondheim, Norway.

This study was supported by grants from the Nature Science Fund of Jiangsu Province and the Fund for Strategic Development of Medical Science and Technology of Nanjing, China.

Received for publication Oct 25, 2007; revisions received Jan 2, 2008; accepted for publication Jan 7, 2008

Address for reprints: Yijiang Chen, MD, Department of Thoracic and Cardiovascular Surgery, The First Affiliated Hospital of Nanjing Medical University, Nanjing, 210029, China (E-mail: yjchen@NJMU. edu.cn).

J Thorac Cardiovasc Surg 2008;136:352-9 $0022-5223 / \$ 34.00$

Copyright $(\underset{2008}{ } 20 y$ The American Association for Thoracic Surgery

doi:10.1016/j.jtcvs.2008.01.014 nuclear factor- $\kappa \mathrm{B}$ in the lungs.

Conclusion: Lung ischemia-reperfusion causes more severe lung damage in infants than in adults, probably because of the combination of low antioxidant capacity and overproduction of reactive oxygen species in infants.

$\mathrm{T}$ The prevalence of congenital heart disease is approximately 4 per 1000 adults and 0.4 per 1000 for those with severe lesions. The prevalence of severe congenital heart disease has increased during the last 20 years. ${ }^{1}$ Open surgery is routinely performed to repair the congenital anatomic defects under total cardiopulmonary bypass. These procedures are inevitably associated with various periods of lung ischemia followed by reperfusion. Ischemia-reperfusion (IR) is well known to result in severe lung injury, which is believed to cause a pulmonary dysfunction with a morbidity of $15 \%$ to $30 \%$ in which more than $2 \%$ of adult patients developed the most severe acute respiratory distress syndrome after open surgery to repair the congenital anatomic defects under cardiopulmonary bypass. ${ }^{2}$ Mortality caused by acute respiratory distress syndrome can be as high as 50\% to 70\%, especially in children with complicated congenital heart diseases and pulmonary artery hypertension. ${ }^{2-6}$ It has been established that the mortality is more than $30 \%$ for adults and approximately $60 \%$ for infants, as a result of pulmonary complications after cardiopulmonary bypass. ${ }^{3}$ Lung IR also takes place during and after lung transplantation and total circulatory arrest. Lung transplantation is infrequently performed with poor outcomes, particularly in infants and children with cystic fibrosis. ${ }^{7,8}$

The mechanisms of IR-induced lung injury have been extensively studied in animal models and humans, showing involvements of neutrophil activation, oxygen free 


$$
\begin{aligned}
& \text { Abbreviations and Acronyms } \\
& \begin{aligned}
\text { GSH-PX } & =\text { glutathione peroxidase } \\
\text { IL } & =\text { interleukin } \\
\text { IR } & =\text { ischemia-reperfusion } \\
\text { MDA } & =\text { malondialdehyde } \\
\text { MyD } & =\text { myeloid differentiation factor } \\
\text { NF- } \kappa \text { B } & =\text { nuclear factor- } \kappa \text { B } \\
\text { ROS } & =\text { reactive oxygen species } \\
\text { ROS-HR } & =\text { reactive oxygen species-hydroxyl radical } \\
\text { SOD } & =\text { superoxide dismutase } \\
\text { TNF } & =\text { tumor necrosis factor }
\end{aligned}
\end{aligned}
$$
ductions of ROS-HR and MDA and activities of GSH-PX and SOD, expression of nuclear factor (NF)- $\kappa \mathrm{B}$, and myeloid differentiation factor (MyD)-88 in the lung were analyzed.
Circulating levels of interleukin (IL)- $1 \beta$ and tumor necrosis factor (TNF)- $\alpha$ were also measured.

\section{Materials and Methods \\ Animals and Experimental Design}

This animal experiment was performed in accordance with the National Institutes of Health "Guide for the Care and Use of Laboratory Animals" and was approved by the Nanjing Medical University Animal Care and Use Committee. Forty-eight New Zealand White rabbits (both genders) were obtained from the Experimental Animal Center of Nanjing Medical University (Nanjing, China). Twenty-four adult rabbits (5-6 months old, body weight $2.5-3.0$ $\mathrm{kg}$ ) and 24 infant rabbits (15-21 days old, body weight $0.6-0.8$ $\mathrm{kg}$ ) were used. All animals were housed with free access to food and tap water under standard conditions with respect to temperature $\left(22^{\circ} \mathrm{C}\right)$, humidity $(60 \%)$, and day/night cycle (12 hour/12 hour) for at least 3 days before experiment. Both adult and infant rabbits were randomly divided into 4 experimental groups: 1) adult sham operation, 2) adult IR, 3) infant sham operation, and 4) infant IR.

\section{Ischemia-Reperfusion Model}

Lung IR was performed according to the method described by Sakuma and colleagues. ${ }^{14}$ In brief, the rabbits were given atropine sulfate $(0.1$ $\mathrm{mg} / \mathrm{kg}$, subcutaneously) and then anesthetized with sodium pentobarbital $(30 \mathrm{mg} / \mathrm{kg}$ in adults and $15 \mathrm{mg} / \mathrm{kg}$ in infants, intravenously administered through the ear vein). Anesthesia was maintained at doses of $10 \mathrm{mg} / \mathrm{kg}$ for adults and $5 \mathrm{mg} / \mathrm{kg}$ for infants. Each rabbit was subjected to cervical tracheotomy with an inserted endotracheal tube and ventilated with room air using a respirator with a tidal volume of $10 \mathrm{~mL} / \mathrm{kg}$ for adults or $12 \mathrm{~mL} / \mathrm{kg}$ for infants and a rate of 30 breaths/ min for adults or 50 breaths/min for infants. The animal was positioned on the left side, and an anterolateral thoracotomy was performed on the right side via the fifth interspace. The right pulmonary hilum was stripped of all neural, vascular, lymphatic, and connective tissue, thereby skeletonizing the right bronchus, pulmonary artery, and pulmonary vein. The inferior pulmonary ligament was divided as it entered the hilum. Heparin was given at a dose of $200 \mathrm{U} / \mathrm{kg}$ in saline intravenously, and 5 minutes later the right pulmonary artery, bronchus, and pulmonary vein were sequentially occluded with noncrushing microvascular clamps to induce ischemia. The clamps were removed after $60 \mathrm{~min}-$ utes, and spontaneous reperfusion with the systemic blood circulation started immediately. Blood samples were taken just before the reperfusion (0) and 1,2, and 4 hours after the reperfusion from the left femoral artery via an arterial puncture needle. The lung was kept moist with intermittent application of saline solution (at room temperature of $\sim 22^{\circ} \mathrm{C}$ ), and the chest incision was covered with plastic film throughout the IR procedure. The sham operation was IR timematched animals that underwent the same procedure, except the clamps were not applied to the hilum. Physiologic saline solution $(0.9 \% \mathrm{NaCl})$ was given subcutaneously $(0.5 \mathrm{~mL} / \mathrm{h}$ for adults and $0.25 \mathrm{~mL} / \mathrm{h}$ for infants) during a period of 4 hours. The right lung from each animal was removed, tissue samples were collected for analyses histologically and biochemically and the animal was killed immediately by intravenous injection of $20 \mathrm{~mL}$ of air for adults and $8 \mathrm{~mL}$ of air for infants.

The mortality of this IR model was $17 \%$ in adults and $50 \%$ in infants, whereas the sham operation caused no death in adults but had $8 \%$ mortality in infants. Most of them died during the reperfusion

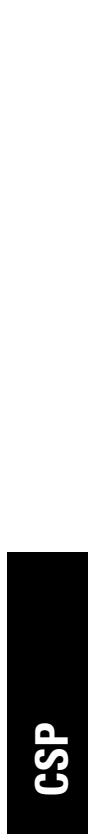

The Journal of Thoracic and Cardiovascular Surgery • Volume 136, Number 2353 
period, especially after approximately 2 hours. For statistical analysis and reported in this article, there were 12 samples in the adult sham operation, 10 samples in the adult IR model, 11 samples in the infant sham operation, and 6 samples in the infant IR model.

\section{Histopathologic Analysis}

For light microscopy, tissue samples were collected from the right lower lung lobe, immersed in $10 \%$ formalin for 18 hours at room temperature, and embedded in paraffin. Sections ( $4 \mu \mathrm{m}$ in thickness) were stained with hematoxylin and eosin. For electron microscopy, small specimens were also taken from the right lower lung lobe and immediately immersed $2.5 \%$ glutaraldehyde in $0.075 \mathrm{~mol} / \mathrm{L}$ sodium phosphate buffer, $\mathrm{pH}$ 7.4. After 2 hours, the specimens were transferred to $1 \% \mathrm{OsO} 4$ and post-fixed for 1 hour, dehydrated in graded acetone, and embedded in Epon 812. Semi-thin sections were cut for identification of the histology, and ultra-thin sections (70-nm thickness) were then cut, contrasted with uranyl acetate and lead citrate, and examined under a JEM-1200 electron microscope (Nihondensi Co., Tokyo, Japan).

\section{Analysis of Mitochondria in the Lung}

Mitochondria were isolated from the lung according to a well-established method. ${ }^{20}$ In brief, the right lung was excised immediately after IR or sham operation, homogenized in isolation buffer containing 225 $\mathrm{mmol} / \mathrm{L}$ mannitol, $75 \mathrm{mmol} / \mathrm{L}$ sucrose, $0.05 \mathrm{mmol} / \mathrm{L}$ ethylenediamine tetraacetic acid, and $10 \mathrm{mmol} / \mathrm{L}$ Tris- $\mathrm{HCl}(\mathrm{pH} 7.4)$ at $4{ }^{\circ} \mathrm{C}$. The homogenates were centrifuged at $600 \mathrm{~g}$ for 5 minutes to remove cell debris and the nuclear fraction. The supernatants were centrifuged at $8800 g$ for 10 minutes, and the pellets were collected and washed twice with the isolation buffer. The isolated mitochondria were used for determinations of mitochondrial swelling, membrane potential, and free $\mathrm{Ca}^{2+}$.

Mitochondrial swelling was assessed by measuring a 540-nm absorbance. The mitochondrial preparations were put in the assay buffer $(0.5 \mathrm{mg}$ protein $/ \mathrm{mL})$ containing $125 \mathrm{mmol} / \mathrm{L}$ sucrose, 50 $\mathrm{mmol} / \mathrm{L} \mathrm{KCl}, 2 \mathrm{mmol} / \mathrm{L} \mathrm{KH}_{2} \mathrm{PO}_{4}, 5 \mu \mathrm{M}$ rotenone, $10 \mathrm{mmol} / \mathrm{L}$ HEPES, and $5 \mathrm{mmol} / \mathrm{L}$ succinate. The extent of mitochondrial swelling was assayed by measuring the decrease in the absorbance at $1,2,3,4$, and 5 minutes after adding $50 \mu \mathrm{M} \mathrm{Ca}^{2+}$ at $30^{\circ} \mathrm{C}$, and the inhibitory rate of mitochondrial swelling was calculated as follows: $(\Delta \mathrm{A}=\mathrm{A} 0 \mathrm{~min}-\mathrm{A}) .^{21}$

Mitochondrial membrane potential difference $(\Delta \Psi \mathrm{m})$ was measured according to the method described by Vander Heiden and colleagues. ${ }^{22}$ Rhodamine 123 is a fluorescent dye that is incorporated into mitochondria in a transmembrane potential-dependent manner. The culture medium was replaced with a new medium containing 5 $\mathrm{mmol} / \mathrm{L}$ rhodamine 123 for 30 minutes in the dark. A mean fluorescence intensity of rhodamine 123 was measured by a fluorescenceactivated cell sorter Canto flow cytometer (Becton Dickinson, San Jose, Calif), and $\Delta \Psi \mathrm{m}$ value was determined. Data were analyzed with the Coulter software package (Phoenix Flow, San Diego, Calif).

Intra-mitochondrial $\mathrm{Ca}^{2+}$ levels were assayed by $\mathrm{Ca}^{2+}$ indicator dye Fluo-3/acetoxymethyl ester (Fluo-3/AM, $10 \mu \mathrm{mol} / \mathrm{L}$, Interchim, Montluçon, France). The mitochondrial preparation was incubated with $10 \mu \mathrm{mol} / \mathrm{L}$ Fluo-3/AM for 30 minutes at $37^{\circ} \mathrm{C}$ in the dark and then washed twice in sodium phosphate buffer. During incubation with Fluo-3/AM, calcium modulators were added to individual tubes. A calcium chelator (Bapta/AM, Sigma, St Louis, Mo) was added for 30 minutes at $37^{\circ} \mathrm{C}$ at a final concentration of $10 \mu \mathrm{mol} / \mathrm{L}$. Fluorescent intensity of Fura-3 was then analyzed by flow cytometry.

\section{Biochemical Analysis of Lung Tissue}

The concentrations of ROS-HR and MDA and the activities of GSH-PX and SOD in the right lung tissue were measured by commercial assay kits (Nangjin Jiancheng Bioengineering Institute, Nangjin, China). The concentrations of ROS-HR and MDA were expressed as nanomoles per milligram of protein and milligrams per gram of protein, respectively. The activities of GSH-PX and SOD were expressed as units per milligram of protein and units per milligram of protein, respectively.

Western blot analysis was used for the determination of MyD88 and NF- $\kappa \mathrm{B}$ in the lung tissue using antibodies against MyD88 (AF3109, R\&D Systems, Inc, Minneapolis, Minn), NF- $\kappa$ B (3037, Cell Signaling Technology Inc, Danvers, Mass), or $\beta$-actin (Bost Bio-engineering Inc, Wuhan, China). The membrane was incubated with horseradish peroxidase-conjugated anti-goat immunoglobulinG (KPL, Gaithersburg, Md) and developed using an enhanced chemiluminescence detection kit (Amersham Pharmacia Biotechnology International Corp, Uppsala, Sweden). Each blot was repeated 3 times. The immunoreactive bands were scanned and normalized by $\beta$-actin bands of the same membrane. The protein expression level was analyzed by AlphaEaseFC software (Alpha Innotech, San Leandro, Calif).

\section{Determination of Serum Concentrations of Tumor Necrosis Factor- $\alpha$ and Interleukin-1B}

Serum was prepared from the blood samples taken from the femoral artery. The concentrations of TNF- $\alpha$ and IL- $1 \beta$ were measured by enzyme-linked immunoabsorbent assay with an enzyme-linked immunosorbent assay kit (Biolegend, San Diego, Calif).

\section{Statistical Analysis}

The results were analyzed with the Statistical Package for the Social Sciences 14.0 (SPSS Inc, Chicago, Ill) and are presented as means \pm standard error of the mean. The differences among the 4 groups were analyzed by 2-way analysis of variance, followed by the SNKq-test. All analyses were performed using statistical software (SAS 9.1.3; SAS Institute Inc, Cary, NC).

\section{Results \\ Histopathologic Alterations in Lung Subjected to Ischemia-Reperfusion}

The lungs subjected to IR in both adult and infant rabbits showed remarkable damages as indicated by capillaries occluded with microthrombi, alveolar and interstitial edema, alveolar space collapse, detached epithelial cells, and increased infiltration of inflammatory cells. The infants appeared to have more severe damage than the adults after IR (Figure 1, $A-D$ ).

Electron microscopy revealed that in adult lungs subjected to IR, type I cells had few and short microvilli on the surface and diluted endoplasmic reticulum in cytoplasm. Type II cells were rich in lamellar bodies. Most mitochondria were enlarged in size, and cristae was broken or disappeared (Figure $1, E-H)$. Endothelial cells in interstitium displayed a clear swollen feature. Infiltrated inflammatory cells were often seen. Compared with adult lungs, the infant lungs in shamoperated rabbits displayed a relatively reduced cytoplasm, 

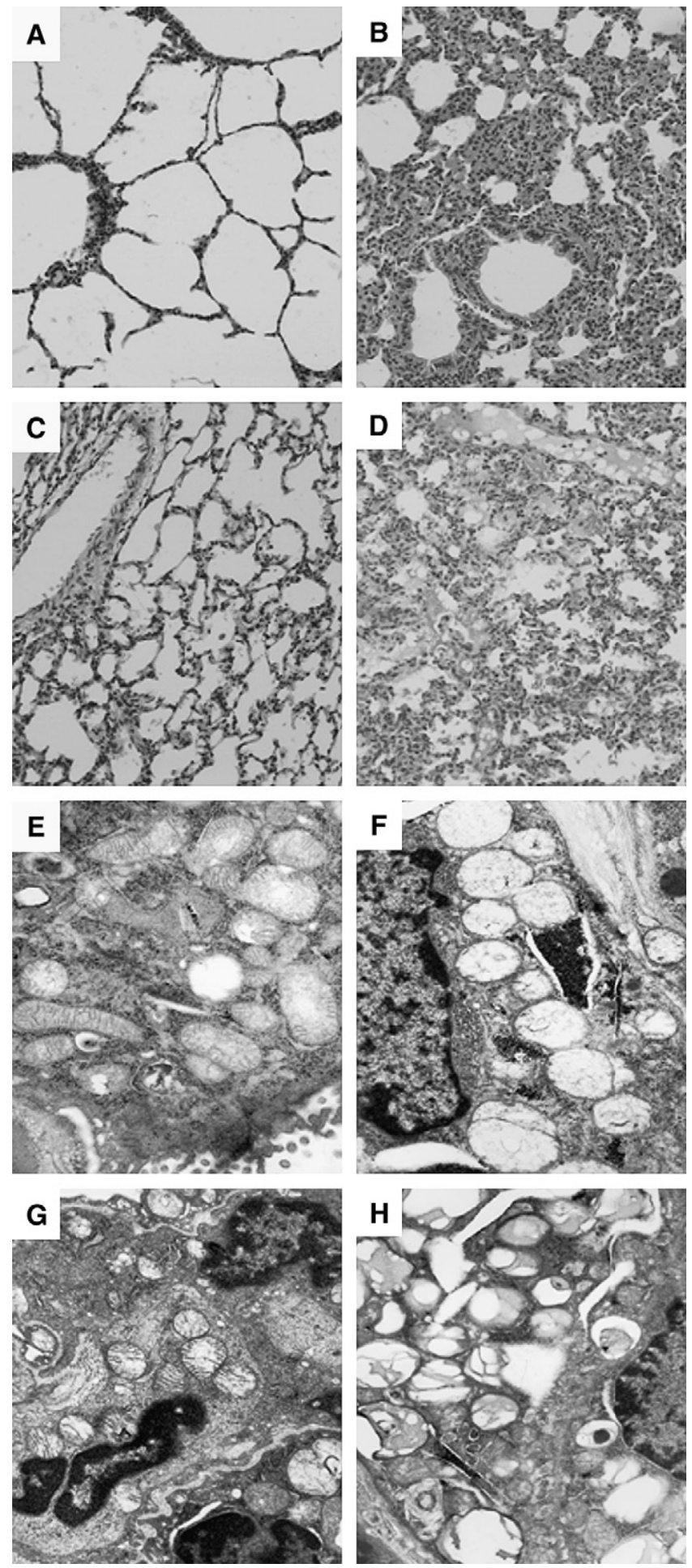

Figure 1. Representative images of light microscopy of lung tissue from sham-operated adult rabbit (A), IR adult rabbit (B), sham-operated infant rabbit (C), and IR infant rabbit (D). Note remarkable alveolar and interstitial edema, alveolar space collapse, detached epithelial cells, and infiltrated inflammatory cells in (B) and (D), and additional capillaries occluded with microthrombi in (D). Hematoxylin and eosin stain, $\times 100$. Representative image of ultra-

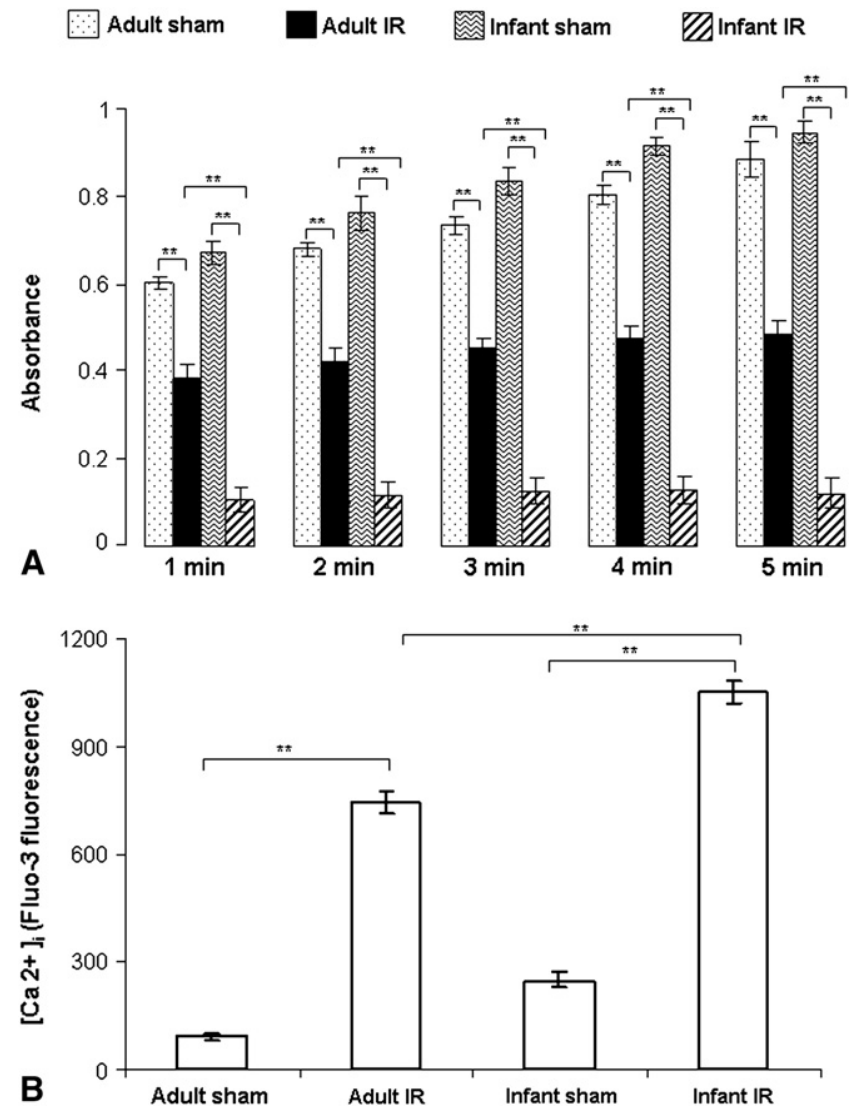

Figure 2. Mitochondrial swelling (540 $\mathrm{nm}$ absorbance) during 1 to 5 minutes (A) and intramitochondrial free $\mathrm{Ca}^{2+}$ concentration measured by using the fluorescent probe fura- $3(B)$ in lungs from sham-operated adult rabbits (adult sham), IR adult rabbits (adult IR), sham-operated infant rabbits (infant sham), and IR infant rabbits (infant IR). Mean \pm standard error of the mean. ${ }^{* *} P<.01$ between adult sham and adult IR or between infant sham and infant IR. Comparison between adult IR and infant IR was also made. IR, Ischemia-reperfusion.

enlarged nuclear profiles, and no or few microvilli on ciliated cells. The cellular organelles were fewer but had relatively normal structure. The IR infant lungs showed greater damages than the IR adult lung, including much swollen mitochondria with disappearance of cristae (Figure 1, $F$ and $H$ ). In addition, necrosis and apoptotic cells were observed.

Mitochondrial Damages in Lung Subjected to Ischemia-Reperfusion

In sham-operated adults and infants, the lung mitochondria were able to swell immediately after adding $50 \mu \mathrm{M} \mathrm{Ca}^{2+}$

structure of lung tissue from sham-operated adult rabbit (E), IR adult rabbit (F), sham-operated infant rabbit (G), and IR infant rabbit $(H)$. Note swollen mitochondria in (F) and near-broken mitochondria in $(H)(\times 10,000)$. 


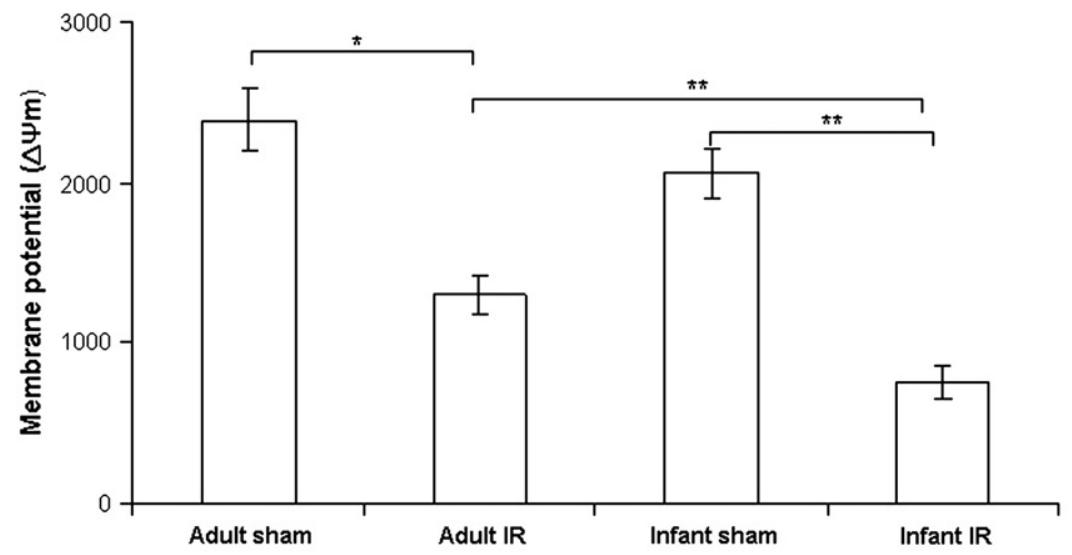

Figure 3. Mitochondria membrane potential $(A)$ in lungs from sham-operated adult rabbits (adult sham), IR adult rabbits (adult IR), sham-operated infant rabbits (infant sham), and IR infant rabbits (infant IR). Mean \pm standard error of the mean. ${ }^{*} P<$ .05 and ${ }^{* *} P<.01$ between adult sham and adult IR or between infant sham and infant IR. Comparison between adult IR and infant IR was also made. Representative records (B) of mitochondria membrane potential in lungs from adult sham, adult IR, infant sham, and infant IR. B, FSC dot plots (left); SSC dot plots (center); histograms of rhodamine-123 fluorescence with intensity values (right). Note the low values in IR
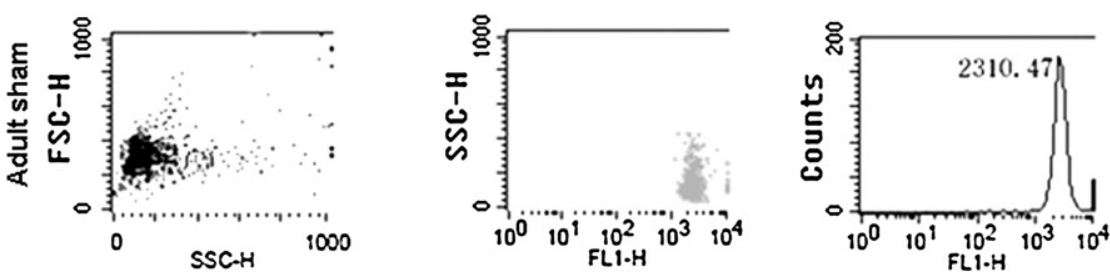
groups. IR, Ischemia-reperfusion; $F S C$ - $H$, forward scatter height; SSC-H, side scatter height.
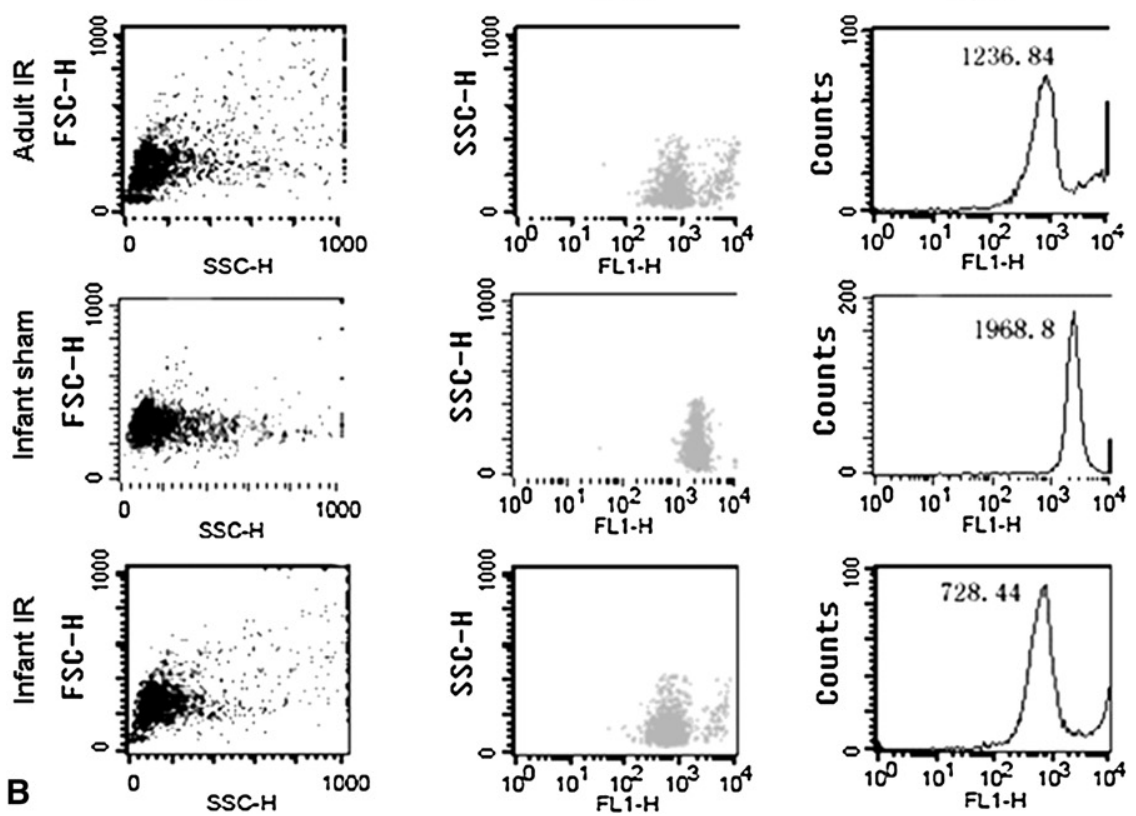

to the medium, and there was no difference between the 2 age groups. In the lungs subjected to IR, a minimal swelling in the adults and no swelling in the infants were detected during the test period from 1 minute to 5 minutes, indicating the nearmaximal or maximal swollen mitochondria in the IR groups (Figure 2, A). Intra-mitochondrial $\mathrm{Ca}^{2+}$ concentration was higher in sham-operated infants than in sham-operated adults. Intra-mitochondrial $\mathrm{Ca}^{2+}$ concentration was increased greatly after IR, especially in the infants (Figure 2, $B)$. Mitochondrial membrane potential $\Delta \Psi \mathrm{m}$ was reduced by approximately $45 \%$ in the adult IR group and by $60 \%$ in the infant IR group $(P<.01$ between adult IR and infant IR) (Figure 3, $A$ and $B$ ).

\footnotetext{
Altered Protein Expression in Lung Subjected to Ischemia-Reperfusion

The concentrations of ROS-HR and MDA were slightly higher in the infants than in the adults (Figure 4, $A$ and $B$ ), whereas the activities of GSH-PX and SOD were lower (Figure $4, C$ and $D$ ). After IR, the levels of MDA and ROS-HR
} 

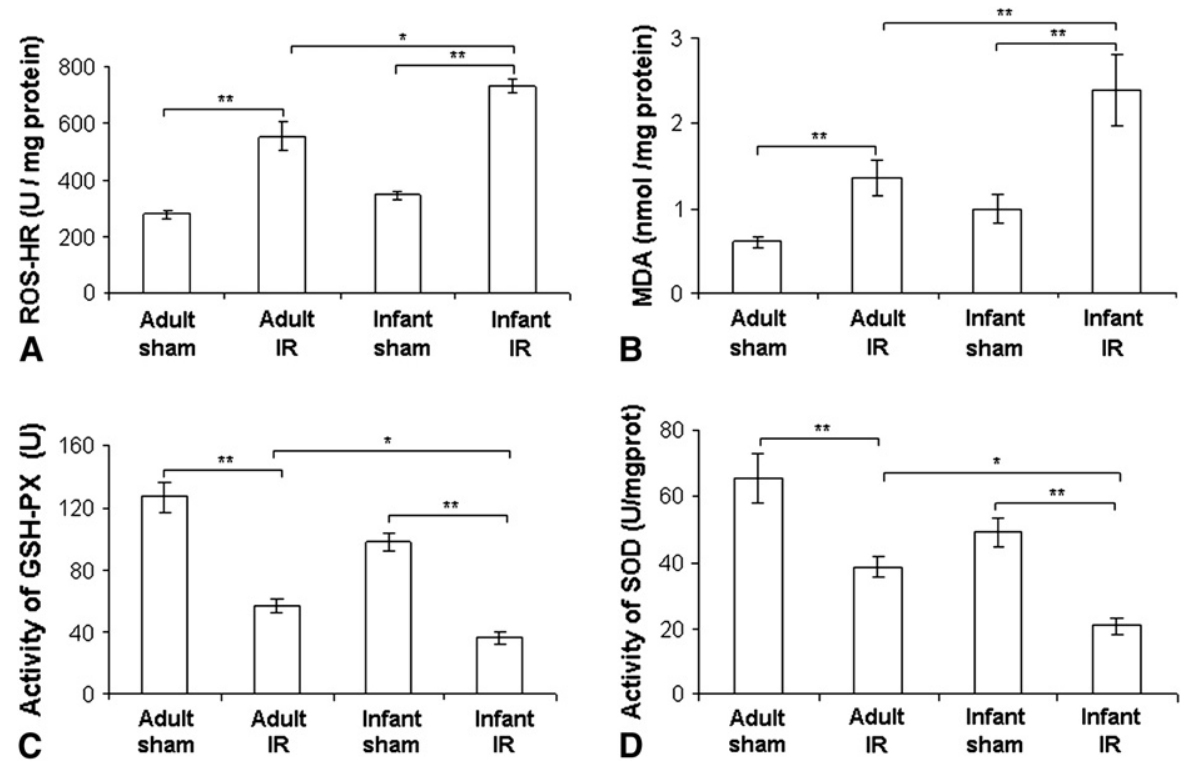

Figure 4. Concentrations of ROS-HR (A) and MDA (B) and activities of GSH-PX (C) and SOD (D) in lungs from sham-operated adult rabbits (adult sham), IR adult rabbits (adult IR), sham-operated infant rabbits (infant sham), and IR infant rabbits (infant IR). Mean \pm standard error of the mean. ${ }^{*} P<.05$ and ${ }^{*} \boldsymbol{P}<.01$ between adult sham and adult IR or between infant sham and infant IR. Comparisons between adult sham and infant sham or between adult IR and infant IR were also made. IR, Ischemia-reperfusion; $S O D$, superoxide dismutase; MDA, malondialdehyde; GSH-PX, glutathione peroxidase; $R O S-H R$, reactive oxygen species-hydroxyl radical. were more elevated in the infants than in the adults, whereas the levels of SOD and GSH-PX activities were more reduced in the infants than in the adults (Figure 4).

\section{Circulating Levels of Tumor Necrosis Factor- $\alpha$ and Interleukin-1ß and Expression of MyD88 and Nuclear Factor $-\kappa B$ in Lung}

Both the serum levels of TNF- $\alpha$ and IL- $1 \beta$ were elevated in response to IR and peaked at 1 to 2 hours after starting reperfusion. The infants had much higher levels than the adults throughout the reperfusion period (Figure 5, $A$ and $B$ ). Moreover, the expression of MyD88 and NF- $\kappa \mathrm{B}$ was increased in the lungs subjected to IR (Figure 5, $C$ ), which was confirmed by the densitometric analysis (Figure $5, D$ and $E$ ).

\section{Discussion}

In the present study using the rabbit model, we have shown that the infant lung is more susceptible than adult lung to IR-induced damage. The infant lung subjected to IR displayed severe morphologic damage in which the mitochondria were most vulnerable, resulting in cell death (both necrosis and apoptosis). It has been suggested that IR-induced mitochondrial damage is mediated by elevated ROS and accumulated $\mathrm{Ca}^{2+}$ inside of the mitochondrial. ${ }^{23,24}$ Ischemia per se is capable of inducing ROS production by pulmonary endothelial cells, but the following reperfusion with the sudden influx of oxygen leads to a burst of ROS, which induces the oxidative stress. In the present study, we found that in comparison with the adults, the infant lung mitochondria produced more ROS (as reflected by elevated ROS-HR and MDA levels) on the one hand and less antioxidant capacity determinants (eg, SOD and GSH-PX) on the other hand. Moreover, we found an increased mitochondrial $\mathrm{Ca}^{2+}$ con- centration in the infants. Thus, we suggest that the combination of $\mathrm{Ca}^{2+}$ overload and ROS overproduction, as well as down-regulation of the antioxidant mechanisms, leads the mitochondria to undergo a "permeability transition" by opening the pores in their inner membrane, causing the mitochondrial swelling, damage, and eventual cell death by necrosis. ${ }^{24}$ As shown in the present study, the infant lungs displayed severe damage of the inner mitochondrial membrane (as evaluated by measuring the mitochondrial swelling), which was associated with the collapse of mitochondrial membrane potential. It can be anticipated that the outer membrane ruptures as swelling proceeds, leading to the release of apoptotic factors, such as apoptosis-inducing factor and cytochrome $\mathrm{c}$, that cause activation of caspase 9 and then caspase 3 , and in turn apoptosis. ${ }^{25}$ Indeed, the apoptotic cells were frequently seen in the lungs subjected to IR, particularly in the infants. The precise molecular mechanisms by which the infant lung was more susceptible than the adult lung to IR are not known at the present. Proteomic analysis of the rest of the lung tissues collected in the present study was performed by 2-dimensional gel electrophoresis and matrix-assisted laser desorption/ionization-time-of-flight mass spectrometry. The results will be presented in a separate report.

Elevated circulating TNF- $\alpha$ and IL- $1 \beta$ levels after IR have been shown to induce a secondary lung injury in IR models of liver, heart, brain, and kidney. ${ }^{26-29}$ A study using a rat model of lung IR showed an increased expression of TNF- $\alpha$ and IL$1 \beta$ in the lung; TNF- $\alpha$ peaked at 2 hours and IL- $1 \beta$ peaked at 4 hours after starting reperfusion. ${ }^{12}$ In the present study, circulating TNF- $\alpha$ and IL- $1 \beta$ levels were elevated during the reperfusion period. It is conceivable that TNF- $\alpha$ and IL- $1 \beta$ play important roles in IR-induced lung damage both locally and secondarily via the blood circulation, which is in agreement 

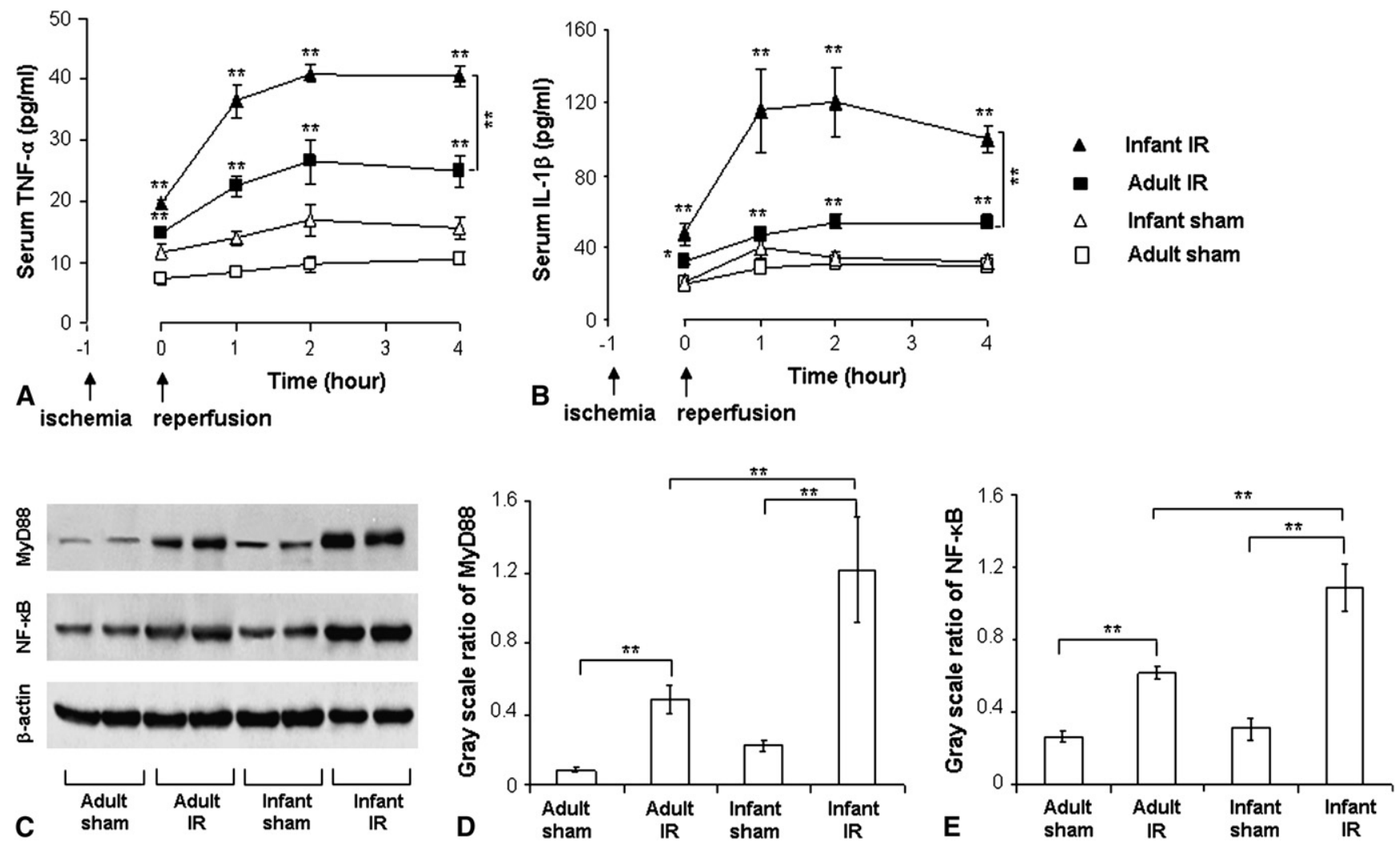

Figure 5. Time course of serum concentrations of TNF- $\alpha$ (A) and IL-1ß (B) immediately (0) and 1, 2, and 4 hours after starting perfusion in adult rabbits subjected to sham-operation (adult sham) or IR (adult IR), and in infant rabbits subjected to sham-operation (infant sham) and IR (infant IR). Western blot of MyD88, NF- $\kappa$ B, and B-actin (C), and densitometric analysis of the expression levels of MyD88 and NF- $\kappa$ B in relation to $B$-actin (D and $E$ ) in the lungs from adult sham, adult IR, infant sham, and infant IR. Mean \pm standard error of the mean. ${ }^{*} P<.05$ and ${ }^{* *} P<.01$ between adult sham and adult IR or between infant sham and infant IR. Comparisons between adult IR and infant IR were also made. IR, Ischemia-reperfusion; $T N F$, tumor necrosis factor; $N F-\kappa B$, nuclear factor- $\kappa$.

with previous reports by others. ${ }^{30,31}$ MyD88 is known to play an important role in toll-like receptors- and the IL-1 receptormediated NF- $\kappa$ B activation pathway. ${ }^{32}$ It has been suggested that this pathway is also involved in myocardial IR injury. ${ }^{33,34}$ In the present study, the expression of MyD88 and NF- $\kappa \mathrm{B}$ was found to be elevated in the lungs after IR, and it was more evident in the infants than in the adults, supporting the view that the MyD88-dependent NF- $\kappa$ B signaling pathway is also involved in IR-induced lung damage.

We suggest that IR induces the infant lung to mitochondrial damages through the mechanisms involving $\mathrm{Ca}^{2+}$ overload and ROS overproduction, the reduction of the antioxidative determinants SOD and GSH-PX, the production of proinflammatory cytokines TNF- $\alpha$ and IL- $1 \beta$, and the activation of the MyD88-dependent NF- $\kappa \mathrm{B}$ pathway. This study shows that the infant rabbits have a lower antioxidant capacity than adults, which may explain why the infant lung is more susceptible than the adult lung to IR-induced damage and why the mortality is much higher in infant than adult rabbits. Apparently, the correlation to human or clinical data remains to be proven.

Mitochondria have been recognized as a target for anti-IR drugs. During the past 10 years, numerous drugs have been developed in an attempt to modulate mitochondrial functions, but few of them are efficient and safe for clinical use, and none have been used in infant patients. Theoretically, novel drugs and procedures must be developed for increasing antioxidative determinants in infants. Alternatively, available free radical scavengers, such as edaravone, can be tested in infants. In a follow-up study, we have found therapeutic effects of edaravone in this infant rabbit model (Qiu W, MD, Zheng L, MD, Zhou J, MD, Chen D, MD, PhD, Chen Y, MD, 2008, unpublished observation).

Dr Wanshan Qiu is a cardiac surgeon at Children's Hospital of Nanjing, China, and currently a doctoral student at Nanjing Medical University and visiting doctoral student at 
the Department of Cancer Research and Molecular Medicine, Norwegian University of Science and Technology. The authors thank Professor Jianwei Zhou at the Department of Molecular Cell Biology and Toxicology, Nanjing Medical University School of Public Health, for support.

\section{References}

1. Marelli AJ, Mackie AS, Ionescu-Ittu R, Rahme E, Pilote L. Congenital heart disease in the general population: changing prevalence and age distribution. Circulation. 2007;115:163-72.

2. Ng CS, Wan S, Arifi AA, Yim AP. Inflammatory response to pulmonary ischemia-reperfusion injury. Surg Today. 2006;36:205-14.

3. Asimakopoulos G, Simth PL, Ratnatunga CP, Taylor KM. Lung injury and acute respiratory distress syndrome after cardiopulmonary bypass. Ann Thorac Surg. 1999;68:1107-15.

4. Haslam PL, Baker CS, Hughes DA, MacNaughton PD, Moat NE, Dewar A, et al. Pulmonary surfactant composition early in development of acute lung injury after cardiopulmonary bypass: prophylactic use of surfactant therapy. Int J Exp Pathol. 1997;78:277-89.

5. Suzuki T, Fukuda T, Ito T, Inoue Y, Cho Y, Kashima I. Continuous pulmonary perfusion during cardiopulmonary bypass prevents lung injury in infants. Ann Thorac Surg. 2000;69:602-6.

6. Bernard GR, Artigas A, Brigham KL, Carlet J, Falke K, Hudson L, et al. The American-European consensus conference on ARDS. Definitions, mechanisms, relevant outcomes, and clinical trial coordination. Am J Respir Crit Care Med. 1994;149:818-24.

7. Boucek MM, Edwards LB, Keck BM, Trulock EP, Taylor DO, Hertz MI. Registry of the international society for heart and lung transplantation: eighth official pediatric report-2005. J Heart Lung Transplant. 2005;24:968-82.

8. Webber SA, McCurry K, Zeevi A. Heart and lung transplantation in children. Lancet. 2006;368:53-69.

9. de Perrot M, Liu M, Waddell TK, Keshavjee S. Ischemia-reperfusioninduced lung injury. Am J Respir Crir Care Med. 2003;167:490-511.

10. Marczin N. The biology of exhaled nitric oxide (NO) in ischemiareperfusion-induced lung injury: a tale of dynamism of NO production and consumption. Vascul Pharmacol. 2005;43:415-24

11. Szeto HH. Mitochondria-targeted cytoprotective peptides for ischemiareperfusion injury. Antioxid Redox Signal. 2007 Nov 13 [Epub ahead of print].

12. Rahman I, Biswas SK, Kirkham PA. Regulation of inflammation and redox signaling by dietary polyphenols. Biochem Pharmacol. 2006; 72:1439-52.

13. Kuratani T, Matsuda H, Sawa Y, Kaneko M, Nakano S, Kawashima Y. Experimental study in a rabbit model of ischemia-reperfusion lung injury during cardiopulmonary bypass. $J$ Thorac Cardiovasc Surg. 1992;103:564-8.

14. Sakuma T, Takahashi K, Ohya N, Kajikawa O, Martin TR, Albertine $\mathrm{KH}$, et al. Ischemia-reperfusion lung injury in rabbits: mechanisms of injury and protection. Am J Physiol Lung Cell Mol Physiol. 1999;276:L137-45.

15. Kim WG, Lee BH, Seo JW. Light and electron microscopic analyses for ischaemia-reperfusion lung injury in an ovine cardiopulmonary bypass model. Perfusion. 2001;16:207-14.
16. Schlensak C, Doenst T, Preusser S, Wunderlich M, Kleinschmidt M, Beyersdorf F. Bronchial artery perfusion during cardiopulmonary bypass does not prevent ischemia of the lung in piglets: assessment of bronchial artery blood flow with fluorescent microspheres. Eur J Cardiothorac Surg. 2001;19:326-32.

17. Krishnadasan B, Naidu BV, Byme K, Fraga C, Verrier ED, Mulligan MS. The role of proinflammatory cytokines in lung ischemia-reperfusion injury. J Thorac Cardiovasc Surg. 2003;125:261-72.

18. Buonocore G, Zani S, Sargentini I, Gioia D, Signorini C, Bracci R. Hypoxia-induced free iron release in the red cells of newborn infants. Acta Paediatr. 1998;87:77-81.

19. Zoban P, Černý M. Immature lung and acute lung injury. Physiol Res. 2003;52:507-16.

20. Aprille JR. Reye's syndrome: patient serum alters mitochondrial function and morphology in vitro. Science. 1977;197:908-10.

21. Lee CS, Han JH, Jang YY, Song JH, Han ES. Differential effect of catecholamines and $\mathrm{MPP}^{+}$on membrane permeability in brain mitochondria and cell viability in PC12 cells. Neurochem Int. 2002;40: 361-9.

22. Vander Heiden MG, Chandel NS, Williamson EK, Schumacker PT, Thompson CB. Bcl-xL regulates the membrane potential and volume homeostasis of mitochondria. Cell. 1997;91:627-37.

23. Morin D, Hauet T, Spedding M, Tillement J. Mitochondria as target for antiischemic drugs. Adv Drug Deliv Rev. 2001;49:151-74.

24. Halestrap AP. Calcium, mitochondria and reperfusion injury: a pore way to die. Biochem Soc Trans. 2006;34:232-7.

25. Martinou JC, Green DR. Breaking the mitochondrial barrier. Nat Rev Mol Cell Biol. 2001;2:63-7.

26. Colletti LM, Cortis A, Lukacs N, Kunkel SL, Green M, Strieter RM. Tumor necrosis factor up regulates intracellular adhesion molecule 1 , which is important in the neutrophil dependent lung and liver injury associated with reperfusion in the rat. Shock. 1998;10:182-91.

27. Gurevitch J, Frolkis I, Yuhas Y, Lifschitz-Mercer B, Berger E, Paz Y, et al. Anti-tumor necrosis factor-alpha improves mycoardial recovery after ischemia and reperfusion. J Am Coll Cardiol. 1997;30:1554-61.

28. Lavine SD, Hoffman FM, Zlokovic BV. Circulating antibody to tumor necrosis factor alpha protects rat brain from reperfusion injury. J Cereb Blood Flow Metab. 1998;18:52-8.

29. Donnahoo KK, Shames BK, Harken AH, Meldrum DR. The role of tumor necrosis factor in renal ischemia reperfusion injury. J Urol. 1999; 162:196-203

30. Zhao M, Fernandez LG, Doctor A, Sharma AK, Zarbock A, Tribble CG, et al. Alveolar macrophage activation is a key initiation signal for acute lung ischemia-reperfusion injury. Am J Physiol Lung Cell Mol Physiol. 2006;291:L1018-26.

31. Kallapur SG, Jobe AH. Contribution of inflammation to lung injury and development. Arch Dis Child Fetal Neonatal Ed. 2006;91:F132-5.

32. Medzhitov R, Preston-Hurlburt P, Janeway CA Jr. A human homologue of the Drosophila toll protein signals activation of adaptive immunity. Nature. 1997;388:394-7.

33. Li C, Ha T, Kelley J, Gao X, Qiu Y, Kao RL, et al. Modulating toll-like receptor mediated signaling by (1->3)-beta-D-glucan rapidly induces cardioprotection. Cardiovasc Res. 2004;61:538-47.

34. Hua F, Ha T, Ma J, Gao X, Kelley J, Williams DL, et al. Blocking the MyD88-dependent pathway protects the myocardium from ischemia/ reperfusion injury in rat hearts. Biochem Biophys Res Commun. 2005; $338: 1118-25$ 